\title{
A study on plain radiography rooms in Sri Lanka with emphasis on radiation protection
}

\author{
W. Nilantha ${ }^{1}$, A.S Pallewatte ${ }^{1}$ J. C. N.Rajendra ${ }^{2}$ \\ ${ }^{1}$ Department of Radiology, National Hospital of Sri Lanka \\ ${ }^{2}$ Department of Physics, Open University of Sri Lanka, Nawala, Nugegoda
}

\section{Abstract}

Aim: To ensure radiation safety, the design of X-ray Rooms require consideration of various aspects including size of the room, shielding requirements, wall thickness, distance from focal spot to operator, the warning light, lead lined doors etc.

Methods: Data was collected from sixty three X-ray rooms in twenty seven hospitals.

Results: Results show $89 \%$ of X-Rooms are larger than recommended size of $20 \mathrm{~m}^{2} .64 \%$ had sufficient wall thickness. Only $12.5 \%$ had warning lights but $95.3 \%$ had lead lined doors. TLD and protective aprons were available in majority of hospitals.

Conclusion: Therefore, some of the plain X-ray rooms surveyed need design improvements to comply with recommended guidelines. A larger detailed study is needed to assess overall impact from these findings on general population.

Key Words: Plain Radiography room; Patient safety; X-ray room design

Correspondence: A.S. Pallewatte asp31263@hotmail.com 


\section{Introduction}

Plain Radiography is the most commonly used modality in Diagnostic Radiology. Xrays utilize electromagnetic radiation having higher energy. Radiation protection is the tool for the protection from biological health hazards from ionizing radiation.

The radiation exposures are classified into occupational exposure (exposure of a person in the workplace), medical exposure (exposure of a person as a part of medical diagnosis) and public exposure (exposures other than medical and occupational).

Annual dose limit for a radiation worker is 20 milisievert and annual dose limit for a member of general public is 1 milisievert ${ }^{1,4}$.

X-ray rooms should be designed and constructed to ensure the safety of operators, other staff and patients. The design of X-ray rooms for diagnostic installations require considerations of various aspects including location of the room, size (length, width, and height), operators' protection and shielding requirements. Walls, doors and windows, require proper shielding mechanism to ensure the radiation protection. Lead and concrete are generally used for X-ray room shielding. It is paramount to follow safety regulations in X-ray room construction and avoid plain conversion of normal rooms into $\mathrm{X}$-ray rooms.

Further protection is achieved by supplementary shielding to protect sensitive organs within the field of view, using filtration to remove soft X-rays etc. Patients receive enormous clinical benefit from a safe diagnostic X-ray examination, although risk cannot be entirely eliminated. Therefore, diagnostic X-rays need justification and optimization in terms of benefit and risks.

Objective of this study is to evaluate the current status in plain radiography rooms in Sri Lanka, identify shortcomings if any and suggest remedial actions. Emphasis is also how these comply with current local and international radiation safety standards where available.

\section{Methodology}

This cross sectional study is based on collecting data from hospitals according to a prepared data sheet. National Hospital of Sri Lanka, all Teaching Hospitals, provincial and district General Hospitals of Sri Lanka were selected for this project (Table 1). There were $63 \mathrm{X}$-ray rooms in the 27 selected hospitals. Each X-ray room was assigned a code depending on hospital category, hospital name and room. Data collected on the data sheet in respect of each hospital were transferred in to a Microsoft Office excel worksheet for data analysis. We collected data on Radiation Protection factors such as availability of lead aprons, gonadal shields, X-ray room size, minimum wall thickness, lead lined doors, warning light, distance between focal spot and control panel, etc. A power tape was used to measure the size of the room (length, width) and the wall thickness. 


\begin{tabular}{|c|c|c|c|}
\hline NAME OF HOSPITAL(Code) & $\begin{array}{c}\text { NO. OF } \\
\text { X-RAY } \\
\text { ROOMS }\end{array}$ & NAME OF HOSPITAL(Code) & $\begin{array}{c}\text { NO. OF } \\
\text { X-RAY } \\
\text { ROOMS }\end{array}$ \\
\hline 1.TH A & 13 & 15.GH A & 02 \\
\hline 2.TH B & 04 & 16.GH B & 01 \\
\hline 3.TH C & 04 & 17.GH C & 01 \\
\hline 4.TH D & 04 & 18.GH D & 01 \\
\hline 5.TH E & 03 & 19.GH E & 02 \\
\hline 6.TH F & 02 & 20.GH F & 02 \\
\hline 7.TH G & 01 & 21.GH G & 02 \\
\hline 8.TH H & 01 & 22.GH H & 02 \\
\hline 9.TH I & 02 & 23.DGH A & 01 \\
\hline 10.TH J & 03 & 24.DGH B & 01 \\
\hline 11.TH K & 02 & 25.DGH C & 01 \\
\hline 12.TH L & 03 & 26.DGH D & 01 \\
\hline 13.TH M & 02 & 27.DGH E & 01 \\
\hline 14.TH N & 01 & & \\
\hline
\end{tabular}

Table 1: Hospitals and number of X-ray rooms considered for data collection.

\section{Results}

\section{Room Size}

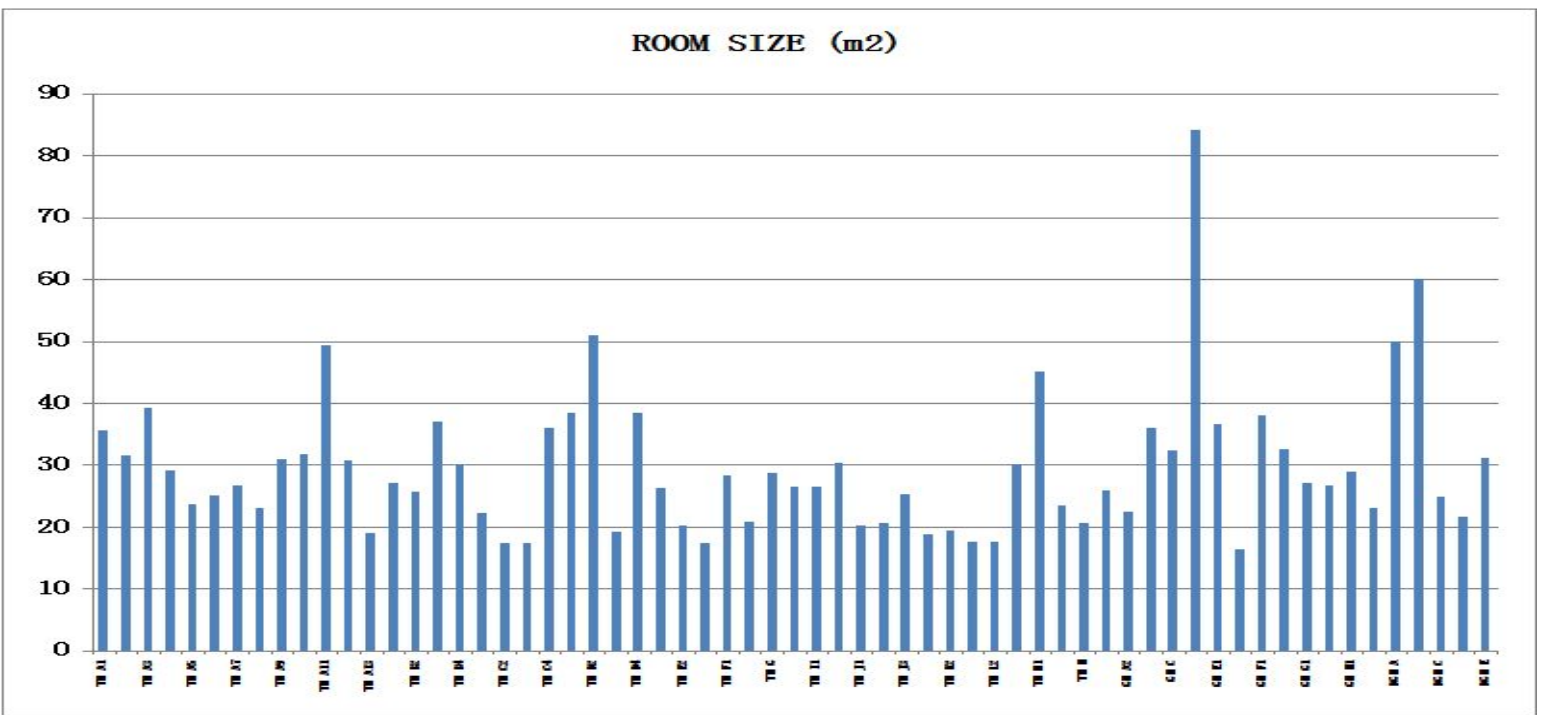

Figure 1.-Variation of room size 


\section{Distance between radiographer/operator and X-ray Tube Focal Spot}

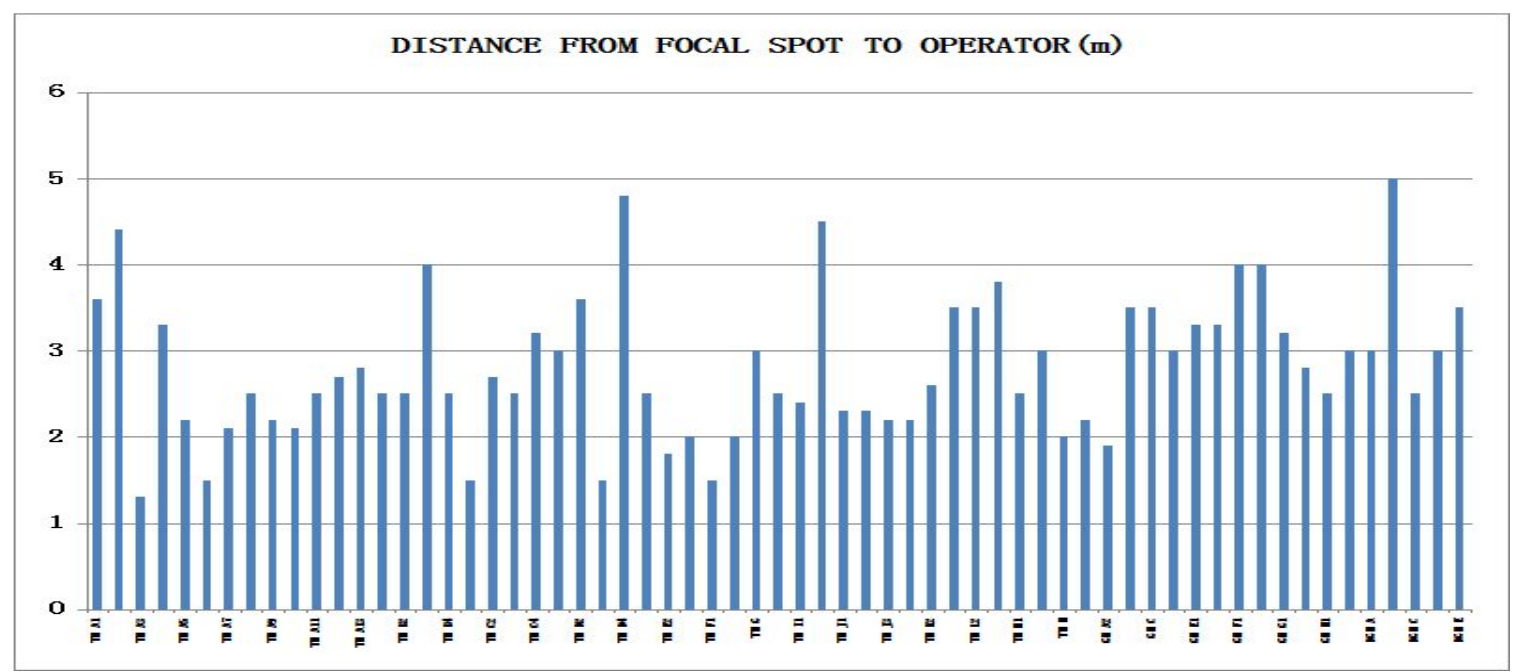

Figure 2-Minimum distance (m) from focal spot of machine to the operator

\section{Wall thickness (cm)}

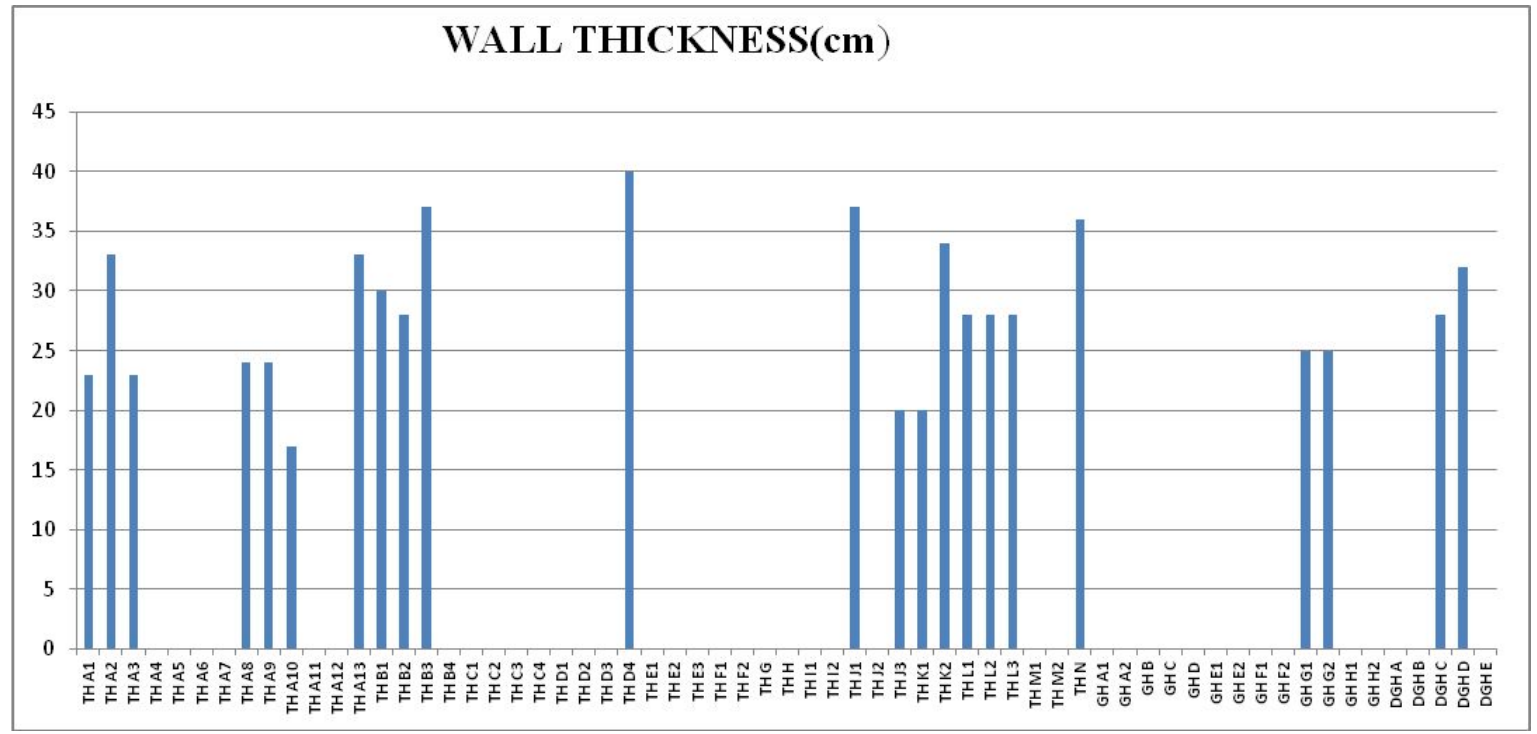

Figure 1 shows that $86 \%$ of the currently available X-ray rooms are above the recommended room size of $25 \mathrm{~m}^{2.1}$

Figure 2 shows that $89 \%$ of the X-ray rooms have more than $2 \mathrm{~m}$ distance between focal spot and the operator ${ }^{2}$.
Figure 3 shows that $36 \%$ of X-Ray rooms do not comply with wall thickness requirements. However complete data was available only from $23 \mathrm{X}$-Ray rooms.

Only $12.5 \%$ of the X-ray rooms among the selected hospitals have functioning warning lights outside room. Lead lined doors were 
available in $96.4 \%$ of the surveyed X-ray rooms. The protective lead aprons are important for personal radiation protection and $97 \%$ of the X-ray rooms had these even though we have no measure on their quality. Gonadal shields for pediatric patient protection was not available in $63 \%$ of the Rooms surveyed. The staff in $95.3 \%$ of Xray rooms were provided with Thermoluminence Dosimeters (TLD's) which is a positive factor as far as staff protection is concerned.

\section{Discussion}

According to the Atomic Energy Authority of Sri Lanka, the acceptable minimum X-ray room size for plain radiography is $20 \mathrm{~m}^{2} .^{1}$ An additional space of $6 \mathrm{~m}^{2}$ minimum is required for a control room, which should be, located separately adjoining to the irradiation room ${ }^{1}$. Around $86 \%$ of the X-ray rooms in the country are complying with the accepted standard. The operator's control room for all radiography procedures should be either in a separate room or in a protective booth, which will intercept the primary beam and scattered radiation. Conversion of the existing rooms straightly as X-ray rooms should be avoided.

The distance between the focal spot of the machine and the operator's console room is also important. The inverse square law determines the appropriate distance, where the intensity of the X-ray beam is reduced with the square of the distance from the Xray tube. According to Atomic Energy Authority of Sri Lanka regulations, the minimum distance should be $2 \mathrm{~m}^{1}$.

As shown in figure 2, 89\% of the currently available X-ray rooms within the selected hospitals comply with the expected distance. $\mathrm{X}$-ray room wall thickness is another physical parameter securing the radiation protection. X-ray room cubicle should be made with $20 \mathrm{~cm}$ thick concrete wall or 30 $\mathrm{cm}$ brick wall as per regulations ${ }^{1,6}$. This requirement is fulfilled in $64 \% \%$ of X-Ray rooms surveyed.

Availability of warning light and lead lined doors are also important for the protection of patients, members of the general public and staff of the hospital. A suitable warning light must be provided outside the X-ray room and kept ' $\mathrm{ON}$ ' when the X-ray unit is in use, to prevent inadvertent entry of persons. Only $12.5 \%$ of the X-ray room among the selected hospitals have warning lights. This could be considered as a drawback since this is the only warning sign which could be installed easily. Ideally adequate number of warning lights systems should be available at all entrances to X-ray rooms and to the patient waiting area.

Doors and door frames leading to X-ray room should be lined with $1.5 \mathrm{~mm}$ lead sheets ${ }^{1,4,6}$. Although $95.3 \%$ of rooms are with lead lined doors even now, it is essential that all the X-ray rooms' doors meet this standard.

Availability of lead aprons and TLD's for protection of the staff was satisfactory. It is important make these available for all the radiation staff and routine quality assurance to ensure their safety effectiveness.

There are several limitations of our study. We could not collect data from government hospitals below general hospital level and any of the private hospitals. Furthermore data collected from some institutions were incomplete. We could not get detailed information on quality assurance programs, radiation leaks and work load.

In conclusion while this article reports current status and an audit of X-ray rooms in the country and suggestions for improvements, it is also important to consider other factors such as work load, 
protective shielding, and quality control programs to ensure better radiation safety. Therefore, to analyze overall impact on radiation safety in Sri Lanka, an in-depth study with emphasis on objective dosimetry is needed.

\section{References}

1. Specifications for Medical Diagnostic X-ray Installations. Atomic Energy Authority of Sri Lanka February 2002. www.aea.gov.lk
2. The physical principles of Medical imaging Patient exposure and dose management. www.sprawls.org/ppmi2/PATDOSE- Online

3. Admassie D, Teferi S, Hailegenaw K. Collective radiation dose from diagnostic $\mathrm{x}$-ray examination in nine public hospitals in Addis Ababa, Ethiopia. Ethiop J Heal Dev 2010:1;24(2).

4. Radiation dose in diagnostic Radiology and methods for dose reduction. International Atomic Energy Agency, Vienna, 1995 April

5. McVey G, Weatherburn H. A study of scatter in diagnostic X-ray rooms. Br J Radiol. 2004;77:2838. http://dx.doi.org/10.1259/bjr/93969091

6. https://rpop.iaea.org/TrainingRadiology/.../RPDI R-L12_Shielding_W... 